\title{
The use of genetic markers for parentage analysis in Passer domesticus (House Sparrows)
}

\author{
JON H. WETTON, DAVID T. PARKIN \& ROYSTON E. CARTER \\ Department of Genetics, University of Nottingham, Queens Medical Centre, Nottingham NG7 2UH, U.K.
}

\begin{abstract}
The relationships between 420 Passer domesticus (house sparrow) nestlings from 144 broods and the adults which fed them were determined using genetic markers. The inheritance and independence of six polymorphic enzymes observed with starch gel electrophoresis and the component bands of DNA fingerprint profiles were investigated, and the probabilities of detecting incorrect parental assignments calculated. Allozymes were capable of detecting cuckoldry by males unrelated to the attendant adult in 54 per cent of cases whilst fingerprints could reveal virtually every occurrence. Fingerprinting uncovered some instances of erroneous parental exclusion based on the allozyme data, highlighting the problems caused by null alleles and post-translational modification. However, both techniques clearly showed that incorrect paternity as a result of extra-pair copulation (EPC) was the sole cause of multiple genetic incompatibilities, and that the cuckoldry rate varied little over 4 years [11.5 per cent $($ s.d. 2.3$)$ ].
\end{abstract}

Keywords: allozymes, DNA fingerprinting, extra-pair fertilization, house sparrow.

\section{Introduction}

The reproductive success of monogamous birds has traditionally been estimated from the number of fledglings raised in an individual's nest. The ease with which this can be measured has encouraged many studies of avian demography and lifetime reproductive success (Newton, 1989). However, an element of uncertainty has been introduced by the widespread discovery of the alternative reproductive strategies of extra-pair copulation (EPC) and intra-specific brood parasitism (IBP). The importance of these behaviours is difficult to quantify by direct observation because both can be carried out quickly and inconspicuously and are thus easily overlooked. This is especially true of extra-pair mating as a single undetected EPC has the potential to fertilize an entire clutch (Birkhead, et al., 1988). Even if every copulation is recorded, successful fertilization is dependent on sperm transfer being achieved and the timing and ejaculate quality of competing inseminations.

In order to determine the reproductive consequences of alternative reproductive strategies, heritable markers must be used to confirm or refute parental assignments based on observed data. Plumage polymorphisms provided the first evidence that EPC can lead to extra-pair fertilization (EPF) in captive mallards (Anas platyrhynchos) (Burns et al., 1980), and provide an easily scored trait for laboratory investigation of sperm competition in zebra finches (Taeniopygia guttata) (Birkhead et al., 1988). However, visual polymorphisms are rarely found in the wild, and have only been used in the case of the blue and white morphs of the lesser snow goose (Anser caerulescens) (Lank et al., 1989) to estimate EPF and IBP rates in large natural populations.

Biochemical polymorphisms occur in all but the most inbred populations and can be detected by starch gel electrophoresis which separates variant forms of an enzyme (allozymes) if they differ in charge. Cases of incorrect parental assignment are apparent when the genotype of a nestling is incompatible with the allozymes of the attendant adult. The probability of a discrepancy arising is dependent on the number of loci surveyed, the number of alleles at each locus, and the frequency of each allele in the population. Unfortunately, only a limited number of loci can be scored from blood samples or muscle biopsies without harm to the donor, and loci encoding polymorphic enzymes typically possess skewed allele frequencies. The frequency of the most common allele often exceeds 0.9 resulting in the majority of individuals sharing a 
limited number of multi-locus genotypes. When both the true parent and attendant adult share an allele found in a nestling, the locus is uninformative in the context of parentage analysis.

The discovery of probes which can simultaneously detect several multi-allelic, hypervariable, minisatellite regions in the human genome has revolutionized the forensic determination of human identity through genetic fingerprinting (Jeffreys et al., 1985b). Subsequently they have been shown to be ideal tools for parentage analysis in vertebrates (e.g. Jeffreys \& Morton, 1987) including birds (Wetton et al., 1987; Burke \& Bruford, 1987; Burke et al., 1989; Birkhead et al., 1990; Westneat 1990; Morton et al., 1990; Gibbs et al., 1990). Alleles at a minisatellite locus vary in the number of tandem repeats of a short (10-60 bp) sequence containing a highly conserved core region. Minisatellite alleles that are liberated from flanking regions by restriction digestion are size-fractionated by agarose electrophoresis, transferred onto a supporting membrane and hybridized to a radiolabelled human-derived probe, which comprises multiple repeats of the core sequence to enable visualization of the allele size distribution. In humans and many other vertebrates, variation is so extensive that only the true parents will possess the combination of bands necessary to reconstruct an offspring's fingerprint profile.

In this paper we will examine the parentage of a large sample of house sparrows (Passer domesticus) nestlings sampled over a 4-year period from a colony at which extensive observations were made of the adults attending each nest. Data from electrophoretic analysis of six protein-encoding loci and DNA fingerprinting were used to determine the frequency of EPF and IBP in the population. In addition, the merits and demerits of each technique are discussed.

\section{Methods}

\section{Field methods}

House sparrows were studied between 1985 and 1988 at Brackenhurst College of Agriculture, $18 \mathrm{~km}$ Northeast of central Nottingham, England. Nestboxes were originally erected in 1980 on a cluster of milking parlours, cattle sheds and garage buildings. Eighty-six were available within the 0.7 ha site during the study period.

Birds were caught with mist and 'bat-fowling' nets (Ennion, 1959) placed across the entrances to barns frequented by foraging sparrows. Those still unringed when breeding commenced were caught with springloaded nest-box traps when the nestlings were 10-15 days old. On first handling, each bird was banded with a uniquely numbered BTO ring and three colour rings to allow individual identification. Blood $(400 \mu \mathrm{l})$ was collected by jugular venipuncture with a preheparinized $2 \mathrm{ml}$ syringe and $16 \mathrm{~mm} 25 \mathrm{G}$ hypodermic. Birds were released approximately $2 \mathrm{~min}$ after sampling. Nestlings were ringed and bled in a similar fashion 10-15 days after hatching. No mortality was observed which could be associated with the sampling procedures. Netting, ringing and bleeding were carried out under licences from the Nature Conservancy Council, British Trust for Ornithology and the Home Office.

Blood samples were collected from 584 nestlings and 692 other birds. The attendant adults at each nestbox were identified by repeated observations of feeding visits to the box. Both adults were identified at 144 broods for which DNA fingerprints were obtained from the adults and every fledgling. These families comprised 420 nestlings, 70 adult males and 62 adult females. Observations outside the nestling period, particularly of copulations, provided corroborating evidence of the putative parent's identity.

\section{Laboratory methods}

Blood samples were transported to the laboratory on the day of collection in a cold box at $\sim 4^{\circ} \mathrm{C}$. Two $15-\mu \mathrm{l}$ aliquots of whole blood were resuspended in $650 \mu \mathrm{l}$ SET ( $150 \mathrm{~mm} \mathrm{NaCl}, 50 \mathrm{~mm}$ Tris/ $\mathrm{HCl}, \mathrm{pH} 8.0 ; 1 \mathrm{~mm}$ EDTA $\mathrm{Na}_{2}$ ) and frozen until required for fingerprint analysis. The remainder was separated into plasma and cellular fractions by $20 \mathrm{~min}$ centrifugation at $2,000 \mathrm{~g}$ at $4^{\circ} \mathrm{C}$. The cellular pellet was resuspended by vigorous vortexing in $250 \mu \mathrm{l}$ of 0.1 per cent Triton X-100 prior to freezing.

\section{Allozyme analysis}

On completing the year's fieldwork, the resuspended cells were thawed and pelleted at $2,000 \mathrm{~g}$ for $40 \mathrm{~min}$ to leave a clear lysate. The lysate and plasma fractions were then divided into $30-\mu 1$ aliquots in individual wells of six replicate microtitre plates. A fresh plate was used for each electrophoresis session. Gel preparation, loading, running and staining followed the methods described in Evans (1987). Details of buffers and running conditions are presented in Table 1 . Staining systems were modified from Shaw \& Prasad (1970) and Harris \& Hopkinson (1976). The polymorphisms are described in detail in Burke (1984) and Wetton (1990). The polymorphic zone in gels stained for general protein is believed to correspond to transferrin on the basis of similarity to patterns published for other species (Burke, 1984). 
Table 1 Electrophoretic conditions used in the allozyme survey

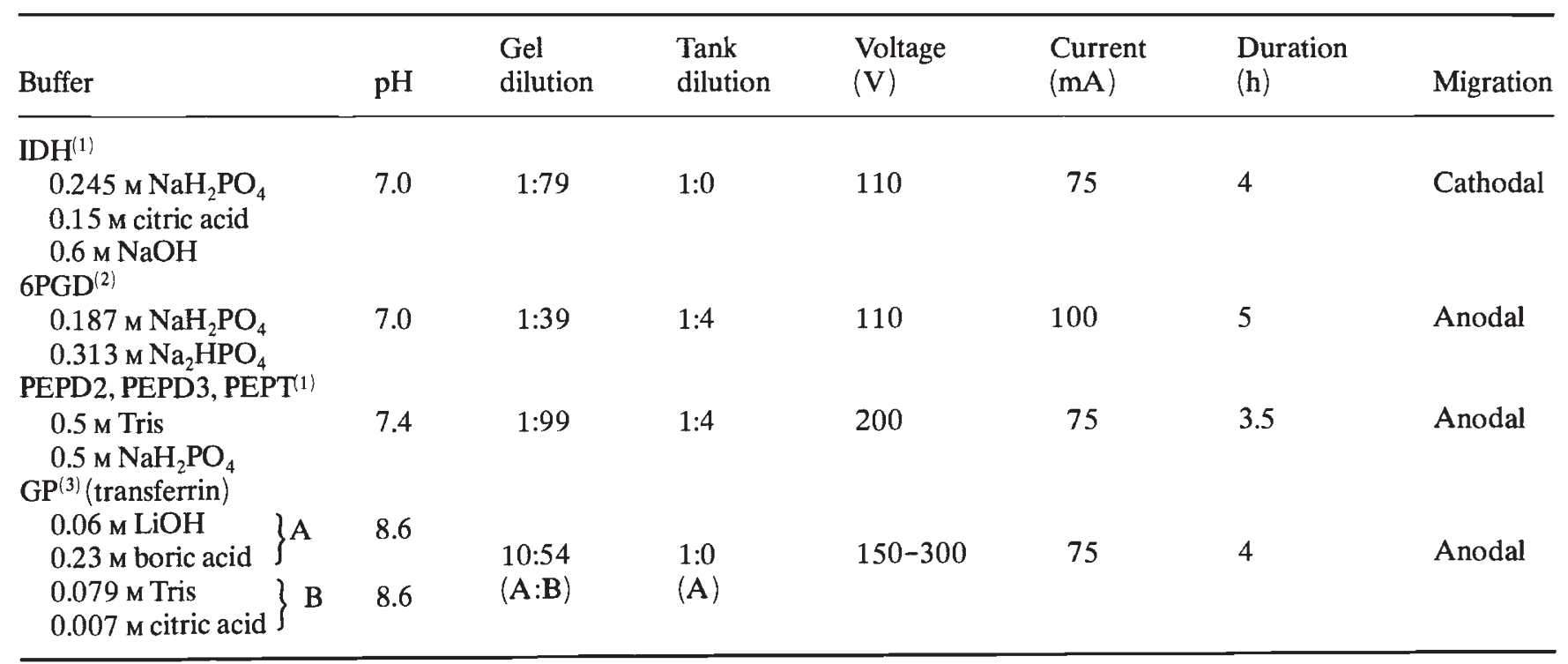

Buffer composition modified from (1) Harris \& Hopkinson (1976), (2) Shaw \& Prasad (1970), (3) Gahne (1966).

\section{Fingerprint analysis}

DNA was extracted from the blood resuspended in SET by overnight incubation with $15 \mu \mathrm{l}$ of $10 \mathrm{mg} \mathrm{ml}^{-1}$ Proteinase $\mathrm{K}$ solution and $7.5 \mu \mathrm{l}$ of 25 per cent SDS (w/v) followed by two phenol, two phenol/chloroform and one chloroform extraction with subsequent ethanol precipitation. The DNA was dried at $37^{\circ} \mathrm{C}$ for $30 \mathrm{~min}$ and resuspended by overnight incubation in $150 \mu \mathrm{l}$ TE $\left(1 \mathrm{~mm}\right.$ EDTA $\mathrm{Na}_{2}, 10 \mathrm{~mm}$ Tris/HC1, pH 8.0). Fifteen microlitres of the redissolved DNA were then digested with $10 \mathrm{U}$ of HaeIII in the presence of 4 mM spermidine in accordance with the manufacturer's instructions. The concentration of the restricted DNA was determined with a Hoefer TKO-100 DNA fluorometer. Six micrograms of restricted genomic DNA were loaded into a $20 \times 22 \mathrm{~cm}, 0.8$ per cent agarose gel in TAE buffer ( $40 \mathrm{~mm}$ Tris, $40 \mathrm{~mm}$ acetic acid, $1 \mathrm{~mm}$ EDTA) pH 8.0 and electrophoresed for $64 \mathrm{~h}$ at $42 \mathrm{~V}$ until fragments smaller than $3.5 \mathrm{~kb}$ were lost from the gel. DNA was then depurinated and denatured in situ by soaking for $20 \mathrm{~min}$ in $0.2 \mathrm{M} \mathrm{HCl}$, followed by 35 $\min$ in $1.5 \mathrm{M} \mathrm{NaCl}, 0.5 \mathrm{M} \mathrm{NaOH}$ and $10 \min$ in $1.5 \mathrm{M}$ $\mathrm{NaCl}, 0.25 \mathrm{M} \mathrm{NaOH}$. Alkaline transfer onto a Hybond $\mathrm{N}$ (Amersham) nylon membrane was achieved by blotting in the latter solution. The DNA was fixed to the filter by baking at $80^{\circ} \mathrm{C}$ for $90 \mathrm{~min}$. Hybridization to radiolabelled RNA transcipts of the polycore sequence from the clone 33.6 (Jeffreys et al., 1985b) subcloned into the pSPT 19.6 derivative is described in Carter $e t$ al. (1989). Autoradiographs were produced by 4-7 days exposure without intensifying screens.

Scoring gels by eye was facilitated by loading the parents on both sides of the gel. Nestling bands were assumed to match those in an adult if they differed in migration by less than $0.5 \mathrm{~mm}$ and their intensity was similar to or fainter than the putative parental band. All nestlings were examined for possession of bands absent from the putative parents which could have arisen through mutation or incorrect parental assignment. A more detailed examination of the segregation of every band larger than $5 \mathrm{~kb}$ was restricted to 36 families (including 199 nestlings) in which the parents possessed at least six clearly defined bands larger than $5 \mathrm{~kb}$. These families were used to determine the number of independently segregating markers. Nonindependence usually arises through linkage or allelism. Linkage results from the cutting of a single minisatellite allele at internal recognition sites to generate two or more fragments which are always coinherited; alternatively two distinct minisatellite regions may be situated close together on a chromosome so that recombination between them occurs infrequently. Allelism of scorable fragments is an unusual phenomenon in many species [e.g. humans (Jeffreys et al., 1985c) and Dunnocks (Prunella modularis) (Burke et al., 1989)]. Due to the extreme variation in allele length at most minisatellite loci, the fragment allelic to a scorable band is usually lost in the mass of smaller, unscored bands. However allelism has been detected in house sparrow fingerprints derived from $A l u$ I digests (Burke \& Bruford, 1987).

Relationships within families were examined using the band sharing coefficient

$$
D=\frac{2 N_{\mathrm{AB}}}{\left(N_{\mathrm{A}}+N_{\mathrm{B}}\right)}
$$


where $N_{\mathrm{A}}$ and $N_{\mathrm{B}}$ are the number of bands in two individuals and $N_{\mathrm{AB}}$ is the number that they share (Wetton et al., 1987). If the majority of bands in a DNA fingerprint are independently inherited the magnitude of $D$ between two individuals will be indicative of their coefficient of genetic relatedness $(r)$. In an ideal situation with an infinite number of alleles at each locus unrelated birds $(r=0)$ would share no alleles whilst first degree relatives $(r=0.5)$ would share 50 per cent. However, the number of alleles is finite, leading to band sharing through chance rather than descent. This results in mean band sharing coefficients which tend to exceed $r$ and less distinction between the proportion of bands shared by birds related to different degrees (Lynch, 1988). Despite this, band sharing can usually discriminate between first degree relatives and unrelateds (e.g. Westneat, 1990). Using this technique we have attempted to ascertain the circumstances leading to multiple mismatches between the fingerprints of nestlings and their putative parents.

\section{Results}

\section{Allozyme analysis}

Birds were grouped by the year in which they were ringed, by age as either nestling, juvenile or adult (survivors of at least one winter) and by sex if adult. The allozyme data were examined for differences in allele frequencies between these subclasses and for deviations from Hardy-Weinberg equilibria. Twentyfour comparisons were made between the sexes ( 4 years $\times 6$ loci) of which two gave large chi-square values, PGD in $1986\left(\chi_{1}^{2}=7.06, P<0.01\right)$ and PEPT in $1986\left(\chi_{5}^{2}=9.43, P<0.05\right)$. Two results of this magnitude are not surprising given the number of tests and only two further significant differences $(P<0.05)$ were found between 1980 and 1984, each at a different locus (Burke, 1984; Wetton, 1990). Therefore, the sexes were combined for subsequent tests. No heterogeneity was found in allele frequencies between years or age classes.

The data, subdivided by age but pooled across years, provided an excellent fit to Hardy-Weinberg expectations, except for nestling transferrin (GP) which was distorted as a result of a highly successful pairing between two rare homozygotes, an AA male and a CC female, which led to an excess of AC nestlings. Withinyear comparisons revealed a few additional distortions but all were explicable through sampling error.

When using allozymes as markers in paternity analysis, it is desirable to confirm that the scoring of zymograms is accurate and that the bands interpreted as alleles are inherited in strict Mendelian fashion. This can only be achieved when the true parentage of a large number of families is known. However, in field studies this situation rarely arises. We have circumvented this problem by retrospectively confirming our initial analyses of linkage and segregation by excluding extrapair offspring (EPO) from the pedigrees. Linkage between loci was examined using the sequential LOD score test (Morton 1955 and 1957) (Table 2). Close linkage $(\theta<0.01)$ could be rejected between all but three pairs of loci for which insufficient informative families were available to determine whether the loci segregated independently.

Within-loci none of the alleles deviated significantly from a 1:1 segregation ratio into the offspring of heterozygous parents. However, two anomalies were discovered. An apparent PEPD3 CC homozygote was produced by a $\mathrm{BC}$ male and what was thought to be a $\mathrm{BB}$ female, yet the fingerprints confirmed these individuals as the true parents. The other unusual finding involved the appearance of bands in nestling transferrin zymograms which co-migrated with a rare allele despite the fact that neither of the biological parents possessed it. Two unrelated broods were involved, each containing two apparent BC heterozygotes produced by $\mathrm{BB}$ homozygous pairs. The possible causes of these discrepancies include mutation, null alleles and post-translational modification of the protein resulting in altered mobility.

Mutations leading to electrophoretically detectable changes are very rare and are unlikely to be encountered in a survey of this size, whereas null alleles occur at low frequencies at many loci, particularly those which overlap considerably in substrate specificity, e.g. esterases and peptidases. PEPD2 and PEPD3 are simultaneously visualized on gels using the same staining substrate, hence a rare null allele at PEPD3 is unlikely to have a substantial deleterious effect on its carrier. The rarity of the PEPD3 C allele strongly implicates the male as the true parent and the female and nestlings as null heterozygotes (e.g. $\mathrm{BC} \times \mathrm{BO} \rightarrow \mathrm{CO})$; this is in agreement with the fingerprint evidence.

Recurrent mutation and null alleles cannot explain the appearance of non-parental transferrin bands in offspring, the most probable explanation of which is the creation of modified molecules derived either from transferrin or another locus with a product sufficiently abundant to be detected by general protein staining. Transferrin phenotypes often required repeated scoring due to the uncertainties raised by heavy subbanding. The precise cause of these discrepancies cannot be confirmed but in future analyses the five nestlings are treated as legitimate offspring.

The efficiency of the starch gel technique at detecting non-parentage was determined using all 420 fingerprinted nestling/adult trios. Twenty-eight nestlings (6.7 
Table 2 An analysis of linkage using LOD scores for a variety of tested recombination frequencies $(\theta)$

\begin{tabular}{|c|c|c|c|c|c|c|}
\hline & \multirow{2}{*}{$\begin{array}{l}\text { Informative } \\
\text { families }\end{array}$} & \multirow{2}{*}{$\begin{array}{l}\text { Informative } \\
\text { offspring }\end{array}$} & \multicolumn{4}{|l|}{$\theta$} \\
\hline & & & 0.01 & 0.05 & 0.10 & 0.20 \\
\hline \multicolumn{7}{|l|}{ 6PGD } \\
\hline P2 & 0 & & & & & \\
\hline P3 & 1 & $2^{*}$ & & & & \\
\hline IDH & 11 & 34 & $<-2$ & $<-2$ & $<-2$ & -1.7406 \\
\hline PT & 2 & 4 & $-1 \cdot 1100$ & & & \\
\hline GP & 6 & 15 & $<-2$ & $<-2$ & -1.1304 & \\
\hline \multicolumn{7}{|l|}{ PEPD2 } \\
\hline P3 & 4 & 10 & $<-2$ & -1.5600 & & \\
\hline IDH & 6 & 19 & $<-2$ & $<-2$ & $<-2$ & -0.8958 \\
\hline PT & 2 & 11 & $<-2$ & $<-2$ & $<-2$ & -0.9691 \\
\hline GP & 6 & 20 & $<-2$ & $<-2$ & $<-2$ & -1.1508 \\
\hline \multicolumn{7}{|l|}{ PEPD3 } \\
\hline IDH & 8 & 26 & $<-2$ & $<-2$ & $<-2$ & -1.1082 \\
\hline $\mathrm{PT}$ & 5 & 21 & $<-2$ & $<-2$ & -1.1566 & \\
\hline GP & 8 & 23 & $<-2$ & $<-2$ & -1.3018 & \\
\hline \multicolumn{7}{|l|}{$\mathrm{IDH}$} \\
\hline PT & 14 & 52 & $<-2$ & $<-2$ & $<-2$ & -0.5230 \\
\hline GP & 19 & 52 & $<-2$ & $<-2$ & $<-2$ & -0.8060 \\
\hline \multicolumn{7}{|l|}{ PEPT } \\
\hline GP & 9 & 37 & $<-2$ & $<-2$ & $<-2$ & -1.2890 \\
\hline
\end{tabular}

LOD scores were calculated using the methods described in Morton 1955 and 1957. Scores $<-2$ provide significant evidence $(P<0.05)$ that the loci are not linked with a recombination frequency of $\theta$ or less, whilst scores $>+3$ are required as significant evidence in favour of linkage at the tested recombination frequency. No linkage was detected, although the limited number of informative pedigrees only permitted the testing of low expected recombination frequencies for some pairs of loci.

*No segregation observed although the number of informative offspring was limited.

per cent) were incompatible with the enzyme genotype of the attendant adults, three of which mismatched at two loci. Incompatibilities were found at every locus especially the more polymorphic ones. Eleven nestlings did not possess the allele present in one of their apparently homozyogous attendants. This cannot be regarded as conclusive proof of non-parentage because of the possibility that parents are heterozygous for rare nulls. However, fingerprinting revealed only one probable case of this, the remaining 10 cases all excluded the male attendant representing a significant difference between the sexes $(10: 0, P<0.005$, twotailed binomial test).

The most parsimonious explanation of the absence of incompatibilities with the female is that they arise solely through cuckoldry of the attendant male. Cases of cuckoldry can go undetected when the attendant male and the true father share alleles. The probability $\left(P_{\mathrm{E}}\right)$ of a detectable incompatibility arising was calculated by a method which allows for differences in allele frequencies between the sexes (Chakraborty et al., 1988). The method assumes that the loci are unlinked, selection is not acting, mating is random and that the female attendant is the true mother. The previous analyses suggest that these conditions are met. The exclusion probabilities are low, which is characteristic of protein encoding loci due to their paucity of allelic variation and skewed allele frequencies. Values ranged from 0.0241 (6PGD) to $0.1704(\mathrm{GP})$. Low $P_{\mathrm{E}}$ can lead to the introduction of large sampling errors when extrapolating from observed mismatches. Hence estimates of EPF rate, based on individual loci, vary between 6.6 and 25.0 per cent (Table 3). However, information gained from independently segregating loci can be combined to raise the probability of detecting cases on non-paternity. The combined probability of exclusion is given by

$P_{\mathrm{E}}(\mathrm{C})=1-\prod_{i=1}^{n}\left(1-P_{i}\right)$

where $P_{i}$ is the exclusion probability associated with the $i$ th of $n$ loci. This gives a value of 0.545 ; high enough to produce a realistic estimate of the EPF rate in each 
Table 3 Allele frequencies and associated exclusion probabilities used to estimate extra-pair fertilization rates

\begin{tabular}{|c|c|c|c|c|c|c|c|c|c|c|c|}
\hline \multirow[b]{2}{*}{ Locus } & \multirow[b]{2}{*}{ Sex } & \multicolumn{5}{|l|}{ Allele } & \multirow[b]{2}{*}{$n$} & \multirow{2}{*}{$\begin{array}{l}\text { Exclusion } \\
\text { probability } \\
P_{\text {E }}\end{array}$} & \multirow{2}{*}{$\begin{array}{l}\text { Observed } \\
\text { exclusion } \\
N_{\mathrm{E}}\end{array}$} & \multirow{2}{*}{$\begin{array}{l}\text { Tested } \\
\text { trios } \\
N_{\mathrm{T}}\end{array}$} & \multirow{2}{*}{$\begin{array}{l}\text { Estimated } \\
\text { EPF rate } \\
(\%)\end{array}$} \\
\hline & & A & B & $\mathrm{C}$ & D & $E$ & & & & & \\
\hline \multirow[t]{2}{*}{ IDH } & M & 0.719 & 0.281 & & & & 363 & 0.1589 & 12 & 402 & 18.8 \\
\hline & $\mathrm{F}$ & 0.691 & 0.309 & & & & 346 & & & & \\
\hline \multirow[t]{2}{*}{ 6PGD } & $\mathbf{M}$ & 0.026 & 0.974 & & & & 365 & 0.0241 & 1 & 397 & 10.5 \\
\hline & $\mathrm{F}$ & 0.049 & 0.951 & & & & 349 & & & & \\
\hline \multirow[t]{2}{*}{ PEPD2 } & $\mathbf{M}$ & 0.055 & 0.945 & & & & 364 & 0.0497 & 5 & 403 & 25.0 \\
\hline & $F$ & 0.046 & 0.954 & & & & 349 & & & & \\
\hline \multirow[t]{2}{*}{ GP } & $\mathbf{M}$ & 0.215 & 0.761 & 0.024 & & & 354 & 0.1704 & 6 & 394 & 8.9 \\
\hline & $F$ & 0.205 & 0.773 & 0.022 & & & 339 & & & & \\
\hline \multirow[t]{2}{*}{ PEPD3 } & $\mathbf{M}$ & 0.014 & 0.891 & 0.023 & 0.070 & 0.002 & 327 & 0.0650 & 5 & 334 & 23.0 \\
\hline & $F$ & 0.008 & 0.930 & 0.008 & 0.054 & 0.000 & 314 & & & & \\
\hline \multirow[t]{2}{*}{ PEPT } & M & 0.001 & 0.037 & 0.021 & 0.925 & 0.012 & 365 & 0.0740 & 2 & 407 & 6.6 \\
\hline & $F$ & 0.003 & 0.044 & 0.037 & 0.907 & 0.006 & 349 & & & & \\
\hline Combined & & & & & & & & 0.5465 & 28 & 389.5 & 13.2 \\
\hline
\end{tabular}

The 31 parent/offspring incompatibilities occurred in 28 trios (including three which mismatched at two loci) after exclusion of the five anomalous mismatches refuted by fingerprinting (see text). Not all trios were scored for every locus due to heavy subbanding, poor activity or insufficient material. The PEPD $3 \mathrm{C}$ allele co-migrates with the PEPD2 A homodimer, thus PEPD3 was not scored in the very rare PEPD2 A homozygotes (identified by the lack of a band at the B allele position) and the more common $\mathrm{AB}$ heterozygotes, which have the typical three-banded appearance diplayed by dimeric enzymes. Individual exclusion probabilities were reduced in proportion to the percentage of trios scored at each locus prior to calculating the combined $P_{\mathrm{E}}$ using the average $N_{\mathrm{T}}$.

Table 4 Comparisons of EPF rate estimates from protein electrophoresis and DNA fingerprinting analysis

\begin{tabular}{|c|c|c|c|c|c|}
\hline \multirow[b]{2}{*}{ Year } & \multicolumn{2}{|c|}{ Observed exclusions } & \multicolumn{2}{|c|}{ Estimated EPF rate $(\%)$} & \multirow{2}{*}{$\begin{array}{l}\text { Number of } \\
\text { fingerprinted } \\
\text { nestlings }\end{array}$} \\
\hline & Enzymes & Fingerprints & Enzymes & Fingerprints & \\
\hline 1985 & 5 & 8 & 13.1 & 10.4 & 77 \\
\hline 1986 & 7 & 14 & 10.5 & 10.6 & 132 \\
\hline 1987 & 12 & 24 & 14.7 & 14.9 & 161 \\
\hline 1988 & 4 & 5 & 15.6 & 10.0 & 50 \\
\hline Total & 28 & 51 & 13.2 & 12.1 & 420 \\
\hline
\end{tabular}

year. These estimates correspond closely with the precise rate determined by DNA fingerprinting (Table 4).

\section{The inheritance of DNA fingerprint patterns}

The fingerprints of the 420 nestling/adult trios were examined for bands unique to the nestling. In 51 trios several mismatching bands (mean $=4.9 \pm 0.5$ ) fell within the region 5-30 $\mathrm{kb}$. These were accompanied by several smaller novel fragments in each case. Three further nestlings possessed just one large novel band within the fingerprint which was assumed to result from mutation, a contention supported by the absence of further mismatches when the trios were examined with a derivative of another polycore probe pSPT 18.15 (Carter et al., 1989).
A more detailed analysis was made of a subset of 36 families comprising unrelated pairs of adults and their 199 nestlings. These included the three 'mutants' and 24 multiple mismatches. The 175 apparently 'legitimate' offspring possessed between them 2,254 scorable bands of which three could not be assigned to a parent. The apparent mutation rate was estimated as $0.0013 /$ band or $0.017 /$ bird. Both are conservative estimates as none of the remaining 221 nestlings possessed a single novel band. Multiple mutations are unlikely since the probability of two independent events occurring in the same bird is $(0.017)^{2}=0.0003$. Therefore cases of multiple non-parental bands are almost certainly the product of incorrectly assigned parentage. The mean number of scorable bands in adult males, females and pulli were $13.7 \pm 0.6(n=36), 10.7 \pm 0.5$ 
$(n=36)$ and $12.9 \pm 0.3(n=199)$, respectively. The difference between the sexes $(t=4.41, P<0.0001)$ cannot be an artefact of band resolution as mated pairs were run in adjacent lanes.

The number of independently segregating haplotypes represented by these bands was estimated using the nine largest sibships to reduce the risk of spurious associations between bands arising by chance (summary data in Table 5). These comprised five full sibships of seven nestlings, and one each of eight, 10,11 and 12 nestlings with no mismatching bands. Cosegregation with a larger band was demonstrated by 21.7 per cent of paternal and 24.0 per cent of maternal fragments (Fig. 1). Up to four bands, but usually only two, formed these co-segregating groups or haplotypes. There was no difference between the sexes in either the number of haplotypes or the number of bands which they contained $(P \approx 0.1, U$-test $)$, whereas 85.7 per cent of cases of allelism occurred in males $(P<0.001$, $n=21$ ). Bands specific to each parent were transmitted to approximately half of their offspring $(47.5$ per cent in 623 scored segregations of 71 maternal bands and 51.7 per cent of offspring in 845 segregations by 103 paternal bands) implying that alleles from different loci rarely co-migrate. Three apparently homozygous bands were excluded from this analysis.

Band-sharing coefficients between unrelated adults were estimated as $0.151 \pm 0.019$ using the 36 mated

Table 5 Summary statistics of fingerprint data from the linkage families

\begin{tabular}{llr}
\hline Parental sex & Male & \multicolumn{1}{l}{ Female } \\
\hline $\begin{array}{l}\text { a Number of bands }>5 \mathrm{~kb} \\
\text { b Number of bands specific } \\
\quad 14.11 \pm 0.77\end{array}$ & $11.22 \pm 1.01$ & $8.33 \pm 0.97$ \\
to parent & $2.44 \pm 0.58$ & $2.00 \pm 0.58$ \\
c Number of sets of linked \\
$\begin{array}{l}\text { co-segregating bands } \\
\text { multiband haplotypes) }\end{array}$ \\
$\begin{array}{l}\text { d Mean number of bands per } \\
\quad 2.22 \pm 0.10\end{array}$ & $2.40 \pm 0.22$ \\
$\begin{array}{l}\text { multiband haplotype } \\
\begin{array}{l}\text { Number of haplotypes } \\
\text { (including single inde- }\end{array}\end{array}$ & $8.78 \pm 0.86$ & $6.33 \pm 0.72$ \\
$\begin{array}{l}\text { pendent bands) } \\
\text { f Number of allelic pairs of } \\
\text { haplotypes }\end{array}$ & $2.00 \pm 0.37$ & $0.33 \pm 0.17$ \\
g Number of independently & $6.88 \pm 0.81$ & $6.11 \pm 0.77$ \\
$\quad$ segregating loci & & \\
\hline
\end{tabular}

Means \pm standard errors were calculated using data from the nine linkage families. The number of haplotypes $(e)$ was calculated as $b-c(d-1)$ and the number of independent loci $(g)$ as $e-f$. The mean proportion of scored unlinked bands $>5 \mathrm{~kb}$ can be derived from $e / b$. pairs and as $0.149 \pm 0.022$ from pairwise comparisons of 16 adjacent fingerprint patterns derived from unrelated males (Table 6). Adults of each sex were compared separately with their legitimate within-pair offspring (WPO) and with those with multiple mismatches (Fig. 2). The band-sharing coefficients between females and nestlings with multiple novel bands fell entirely within the 99 per cent confidence range for female/WPO comparisons, whereas none of the multiple mismatches was within the 99 per cent confidence range for male/WPO comparisons. In addition the band-sharing coefficients between multiple mismatches and their male attendants fell entirely within the range found between unrelateds (data not shown). The comparisons with attendants of each sex confirms the expectations derived from the electrophoretic survey that all mismatches are the result of cuckoldry rather than egg dumping or 'quasi-parasitism' (Wrege \& Emlen, 1987).

The estimate of band sharing between first degree relatives $(r=0.5)$ derived from the mean of parent/ offspring comparisons is very similar to the mean of full-sib comparisons. Half-sibs (e.g. nestlings sharing the same mother but different fathers as a consequence of EPC) are second-degree relatives $(r=0.25)$ and are thus expected to be intermediate in their band sharing between the first-degree relatives and unrelated birds. A very close linear relationship between band sharing and the proportion of alleles shared by direct descent is revealed by regressing the observed mean values of band sharing $(\bar{D})$ between unrelateds, and first- and second-degree relatives on $r$ (see Fig. 3). The residual band-sharing between unrelateds is a reflection of the finite number of alleles and the limited resolution achievable with Southern blotting.

On average, nestlings shared fewer bands with their mothers than their fathers. The difference, though small, was highly significant $[1.6 \pm 0.31$ (S.E.M.) band, $P<0.0001]$. This finding and the presence of three additional bands and two more allelic pairs in the fingerprints of males can be explained by sex linkage. As males are the homogametic sex in birds, they possess two copies of each Z-linked locus. Each Z-chromosome must contribute approximately three fragments larger than $5 \mathrm{~kb}$, derived from loci at which large alleles predominate to account for the greater number of bands and more frequent allelism in males.

If we assume that each Z-chromosome carries three scorable fragments then the average individuals has 7.7 autosomal bands and either six or three sex-linked bands depending on whether it is male or female. Male offspring inherit 3.85 autosomal and three sex-linked bands from each parent. Thus, if there was no band sharing between the parents the similarity coefficients 


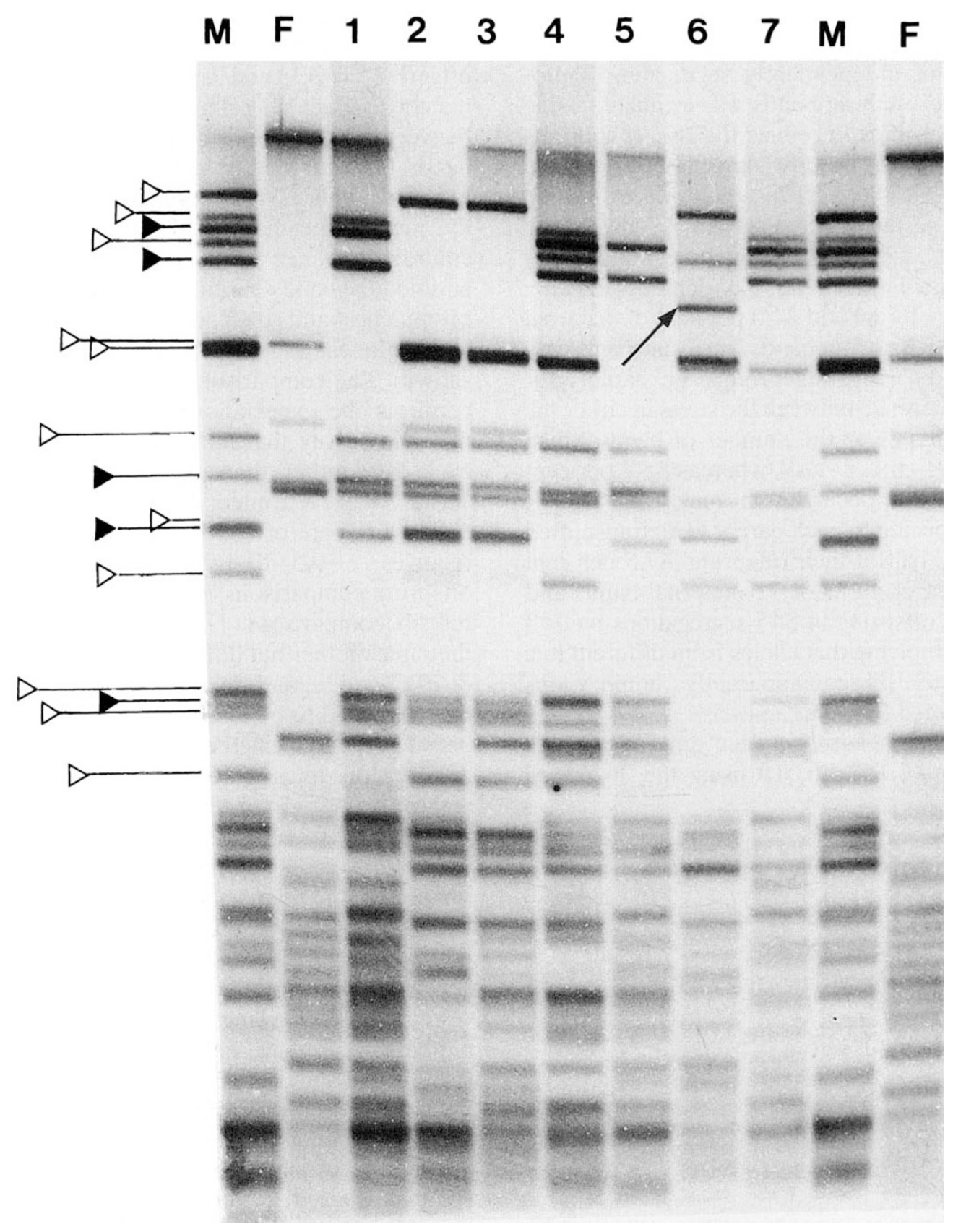

Fig. 1 DNA fingerprints produced by hybridization to pSPT19.6 showing the segregation of parental bands $(\mathrm{M}=$ male, $F=$ female) within a sibship of seven sparrows (1-7). All seven maternal bands larger than $5 \mathrm{~kb}$ segregated independently. However, the 16 paternal bands included several non-independent groups indicated by lines of equal length. These could be derived from only six loci including two giving multi-banded allelic haplotypes (shown as solid and outline arrowheads). One band in nestling six is absent from both parental fingerprints and must have arisen by mutation. The parentage of individual six was confirmed by reprobing with pSPT18.15 and was further supported by the absence of incompatible allozymes. 


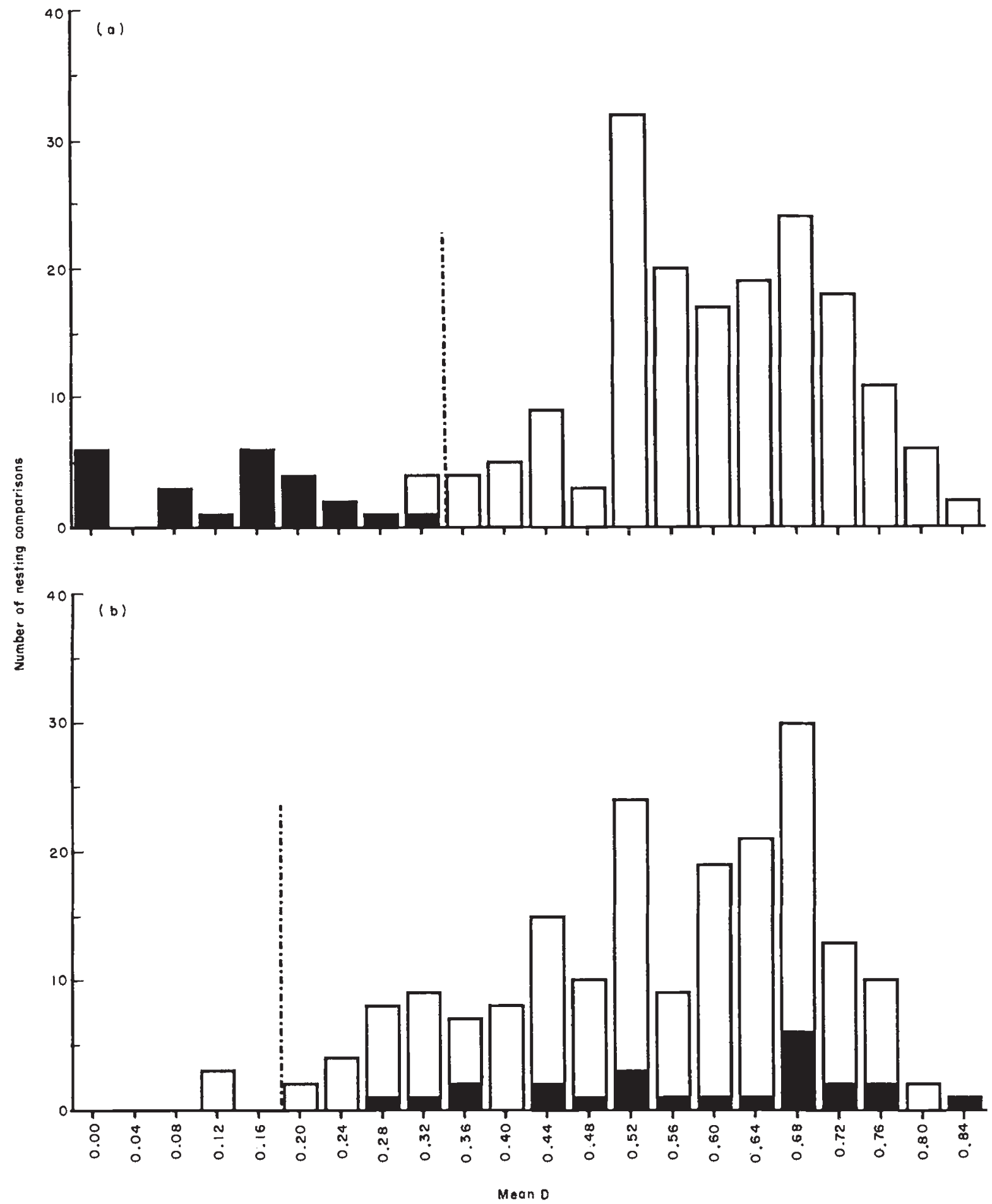

Fig. 2 A comparison of the band-sharing proportions between nestlings with no mismatches (including those with single mutant bands) and nestlings with multiple unassignable bands with (a) their male attendant, and (b) their female attendant. One-tailed 99 per cent confidence limits were calculated assuming a normal distribution for the range of band-sharing coefficients between adults and their offspring (using nestlings with less than two novel bands). The proportion of bands shared with all 24 multiple mismatches fell within the range observed for 'legitimate' offspring for the female attendant but none of them fell within the male/offspring range. The range is greater for female/offspring comparisons due to probable sex linkage of some bands (see text). (ㅁ) WPO, ( $\mathbf{a})$ EPO. 


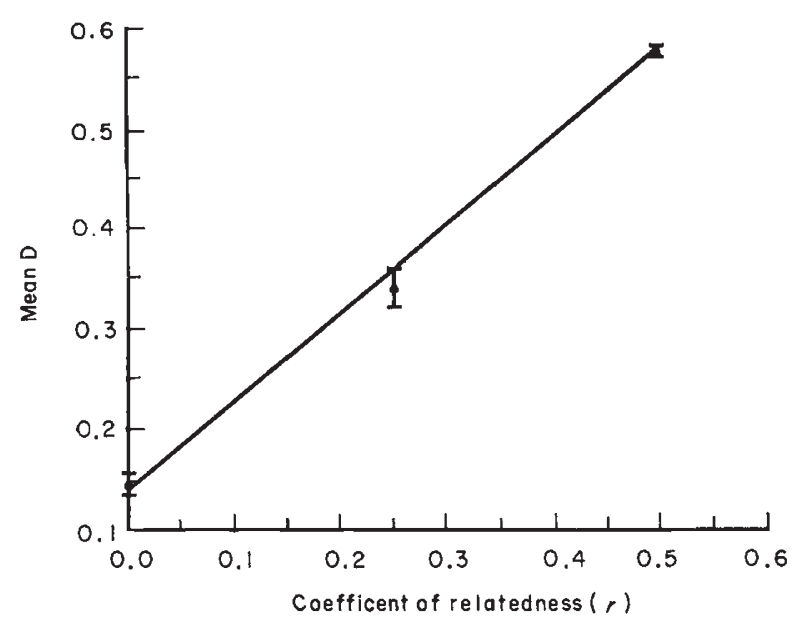

Fig. 3 The relationship between the coefficient of relatedness $(r)$ and the band-sharing coefficient $(D)$. The mean for unrelateds $(r=0)$ was calculated using categories a,b and $\mathrm{g}$ from Table 6 , the half-sib class $(f)$ was used for seconddegree relatives $(r=0.25)$ and the mean for first-degree relatives $(r=0.5)$ was estimated from both parent/offspring (c,d and $\mathrm{h}$ ) and full-sib comparisons (e). The means \pm s.d. are shown with a fitted linear relationship $D=0.139+0.871 r$ $(t=24.43, n=969, P<0.0001)$ which passes very close to the expected $D=1$ when $r=1$.

would be:

$\begin{array}{ll}\text { Father/son } & \frac{2(3.85+3)}{(13.7+13.7)}=0.5, \\ \text { Mother/son } & \frac{2(3.85+3)}{(10.7+13.7)}=0.578, \\ \text { Father/daughter } & \frac{2(3.85+3)}{(13.7+10.7)}=0.578 .\end{array}$

However, mothers make no contribution of Z-linked alleles to their daughters.

Mother/daughter $\frac{2(3.85+0)}{(10.7+10.7)}=0.360$.

If we further assume an equal sex ratio, the mean band sharing between nestlings and their parents would be $(0.5+0.578) / 2=0.539$ with fathers and $(0.578+0.360) / 2=0.469$ with mothers. Adjusting the estimates to account for the average 15 per cent band sharing between mates using $D_{15 \%}=\mathrm{D}_{0 \%}+0.15$ $\left(1-D_{0 \%}\right)$ gives estimates of 0.608 and 0.549 for fathers and mothers respectively, which are very close to the observed values of 0.598 and 0.536 , respectively (Table 6).

Surprisingly, neither the number of haplotypes nor the mean number of bands within each haplotype
Table 6 Summary of the similarity coefficient $(D)$ analysis of the Brackenhurst family data

\begin{tabular}{llr}
\hline Relationship & Mean $D \pm$ s.e. & $n$ \\
\hline a Male/female & $0.1511 \pm 0.0186$ & 36 \\
b Male/male & $0.1492 \pm 0.0216$ & 16 \\
c Male/WPO & $0.5983 \pm 0.0085$ & 173 \\
d Female/WPO & $0.5362 \pm 0.0118$ & 173 \\
e WPO/WPO & $0.5802 \pm 0.0086$ & 451 \\
f WPO/EPO & $0.3411 \pm 0.0193$ & 76 \\
g Male/EPO & $0.1370 \pm 0.0218$ & 24 \\
h Female/EPO & $0.5775 \pm 0.0309$ & 24 \\
\hline
\end{tabular}

The basal level of band sharing between putative unrelated individuals was estimated from the mean similarity coefficient between (a) the two mated birds from 36 pairs and (b) 16 pairwise comparisons of adjacent fingerprint patterns derived from males chosen at random from the aforementioned pairs. The similarity between first-degree relatives was estimated from comparisons of $(\mathrm{c})$ fathers and their 'legitimate' offspring (WPO) (d) mothers and WPO and (e) 'legitimate' full sibs. Females were equally similar to their EPO ('illegitimate' offspring) and WPO [(h) and (d) respectively] implying the attendant female was always the mother. Males compared with EPO in their broods (g) gave similarity coefficients characteristic of unrelated individuals. EPO and their attendants 'legitimate' offspring (f) were clearly second-degree relatives from the intermediate value of the similarity coefficients (between first-degree relatives $r=0.5, \bar{D}=0.58$ and unrelateds $r=0, \bar{D}=0.15$ ).

varies between the sexes. If the bands originated from a single locus, or several situated in a tight cluster, males would possess more linkage groups and a mean haplotype size closer to three bands. Alternatively, if the bands originated from loci dispersed over the length of the region unique to the $\mathrm{Z}$-chromosome, recombination between loci could occur in males resulting in independent segregation, whereas the Z-linked loci in females could not recombine and would be inherited as a single three-banded haplotype. An intermediate state in which limited recombination occurs in males could produce the observed pattern of linkage. Further clarification of this problem awaits the acquisition of additional large families, sex-specific probes to determine progeny gender, and identification of the Z-linked fragments.

\section{Exclusion probabilities}

Using the observed probabilities of band sharing between unrelated individuals of 0.15 and first-degree relatives of 0.58 , we can estimate the probability that an incorrectly assigned male will share all of an EPO's paternal bands with the true father. From previous 
analyses the average nestling possesses 13 scorable bands of which approximately 15 per cent are shared by both parents (i.e. 1.95 bands), of the remainder, 23 per cent are co-inherited with a larger band. Excluding these leaves 8.4 unlinked bands. As a conservative estimate, we shall assume that 50 per cent of the bands originate from the male even though daughters are likely to share more bands with their father. Therefore the average nestling possesses 4.2 independently inherited parent-specific bands $>5 \mathrm{~kb}$. The probability of every paternal band being present in an unrelated male is $0.15^{4.2}$, which corresponds to an exclusion probability of 99.96 per cent. If the true father was a first-degree relative of the attendant male, the greater number of bands shared through common ancestry reduces the exclusion probability to 0.90 (i.e. $\left.1-0.58^{4.2}\right)$. To allow for the possibility of a single mutation, the number of paternal-specific bands can be reduced from 4.2 to 3.2 . This still results in a satisfactory exclusion probability of 99.8 per cent for cuckoldry by unrelated males but only 83 per cent for close relatives. We are confident from our ringing data that cuckoldry by close kin will occur so rarely as to have a negligible effect on the estimated EPF rate.

The minimum of two mismatching bands $(>5 \mathrm{~kb})$ was found in a pair of nestlings which, like their mother, possessed only six large fragments. In these cases, as in all others of multiple novel bands, additional unassignable bands were clearly resolved in the region $3-5 \mathrm{~kb}$, at least four paternal specific bands were observed in every EPO profile. Even with the very conservative limitation of only scoring bands $>5$ $\mathrm{kb}$, the 'worst case' exclusion probability encountered was $0.98\left(1-0.15^{2}\right)$ for cuckoldry by an unrelated male. No further mismatches were detected when 190 apparently 'legitimate' nestling/parent trios selected using these exclusion criteria were subsequently screened with a panel of hypervariable single locus probes (J. H. Wetton \& T. Burke, unpublished data).

\section{Discussion}

The biochemical tests of parentage are in close agreement, although the results from the more powerful fingerprint analysis proved considerably more informative. Despite substantial changes in population density and operational sex ratio (J. H. Wetton unpublished data), the EPF rate varied little between years. The precise distribution of EPO between pairs, broods and during the course of an individual season are discussed elsewhere (Wetton \& Parkin, 1991). Surprisingly no evidence of successful IBP was found despite its occurrence in other populations (Manwell \& Baker, 1975; D. Harper personal communication). In
Harper's population the number of preferred nest sites (i.e. nestboxes) is limited and he has observed that females occupying predation-prone nests in hedgerows frequently dump eggs in the boxes. At Brackenhurst, about 50 per cent of nestboxes are unoccupied each year, thus females may have little to gain from egg dumping in the near absence of nest predation, only three suspected cases of which have been noted in 6 years. Many of Harper's females also solicited EPC; in the case of dumping females, the cuckolding male was often the resident male in whose nest the eggs were laid. Cases of 'quasi-parasitism' (Wrege \& Emlen, 1987), in which the resident male is the true sire but the attendant female is unrelated to the nestling, were not detected at Brackenhurst. Every EPO was more closely related to the attendant female than the male.

The widespread occurrence of EPC (Birkhead et al., 1987) emphasizes the need for a generally applicable technique to test the parentage of nestlings sampled in the wild which does not depend on observation alone. Protein electrophoresis is relatively cheap and simple, and published protocols exist for staining a wide variety of enzymes which are easily adapted for each new species. However, very few polymorphic loci can be sampled non-destructively, and thus the exclusion probabilities are low. In some cases, intra-population variation is so limited that EPF rates cannot be estimated (e.g. Mumme, et.al., 1985). Fingerprinting is capable of detecting incorrect parental assignment even when the putative parents are close relatives (Jeffreys et al., 1985a) or the population is inbred and most allozyme variation has been lost. On the deficit side, fingerprinting is expensive and time consuming, the use of radioactive probes also necessitates specialist facilities (e.g. radioisotope laboratories) although non-radioactive detection methods are becoming more reliable (Zischler et al., 1989). Analyses based on either technique require some knowledge of the inheritance pattern of the markers. Detection of non-independent segregation requires large families of known parentage: a luxury which is seldom available. Despite this, realistic estimates of $P_{\mathrm{E}}$ must take into account the reduction in the number of independent markers caused by linkage. Mutations at protein encoding loci are sufficiently rare as to have little effect on parentage analyses, and at fingerprint loci they can usually be recognized as such because they result in only a single mismatching band. However, errors in scoring zymograms present a much greater problem, as a single misscored allozyme will mimic incorrect parental assignment whereas in a fingerprint it mimics a mutation: thus fingerprinting is more robust to errors. In summary, DNA fingerprinting represents a major advance over the previously existing methods for avian 
parentage analysis, although these techniques may still prove useful in reducing the number of individuals it is necessary to screen when searching for unidentified biological parents.

\section{Acknowledgements}

We would like to thank Professor A. J. Jeffreys for the original minisatellite probes and the Principal and staff at the Brackenhurst College of Agriculture for allowing us to work at their farm. D. Walters helped greatly with the fieldwork, and Dr T. Burke provided many helpful comments. The work was funded by NERC and SERC. The Jeffreys probes 33.6 and 33.15 and their derivatives are the subject of patent No. GBA Z166445 and world-wide patents (pending) for commercial diagnostic use.

\section{References}

BIRKHEAD, T. R., ATKIN, T. L. AND MøLLER, A. P. 1987. Copulation behaviour of birds. Behaviour, 101, 101-138.

BIRKHEAD, T. R., BURKE, T., ZANN, R., HUNTER, F. M. AND KRUPA, A. P. 1990. Extra-pair paternity and intraspecific brood parasitism in wild Zebra Finches Taenopyia guttata, revealed by DNA fingerprinting. Behav. Ecol. Sociobiol, 27, 315-324.

BIRKHEAD, T. R., PELLATT, J. AND HUNTER, F. M. 1988. Extra-pair copulation and sperm competition in the Zebra Finch. Nature, 334, 60-62.

BURKE, T. 1984. The ecological genetics of two populations of the house sparrow Passer domesticus. PhD Thesis, University of Nottingham.

BURKE, T. AND BRUFORD, M. W. 1987. DNA fingerprinting of wild birds. Nature, 327, 149-152.

BURKE, T., DAVIES, N. B., BRUFORD, M. W. AND HATCHWELL, B. J. 1989. Parental care and mating behaviour of polyandrous Dunnocks Prunella modularis related to paternity by DNA fingerprinting. Nature, 338, 249-251.

BURNS, J. T., CHENG, K. M. AND McKINNEY, F. M. 1980. Forced copulation in captive Mallards. I. Fertilization of eggs. Auk, 97, 875-879.

CARTER, R. E., WETTON, J. H. AND PARKIN, D. T. 1989 Improved genetic fingerprinting using RNA probes. Nucl. Acids Res. 17(14), 5867.

CHAKRABORTY, R., MEAGHER, T. R. AND SMOUSE, P. E. 1988. Parentage analysis with genetic markers in natural populations. $I$. The expected proportion of offspring with unambiguous paternity. Genetics, 188, 527-536.

ENNION, E. A. R. 1959. The House on the Shore. Methuen London.

EVANS, P. G. H. 1987. Allozyme variation. In: Cooke, F. and Buckley, P. A. (eds) Avian Genetics. Academic Press, London.

GAHNE, B. 1966. Studies of the inheritance of electrophoretic forms of transferrin, albumin, pre-albumin and plasma esterases of horses. Genetics, 53, 681-694.
GIBBS, H. L., WEATHERHEAD, P. J., BOAG, P. T., WHITE, B. N., TABAK, L. M. AND HOYSAK, D. J. 1990. Realized reproductive success of polygynous Red-Winged Blackbirds revealed by DNA markers. Science, 250, 1394-1397.

HARRIS, H. G. AND HOPKINSON, D. A. 1976. Handbook of Enzyme Electrophoresis in Human Genetics. North-Holland, Amsterdam.

JEFFREYS, A. J., BROOKFIELD, J. F. Y. AND SEMEONOFF, R. 1985a. Positive identification of an immigration test-case using human DNA fingerprints. Nature, 317, 818-819.

JEFFREYS, A. J. AND MORTON, D. B. 1987. DNA fingerprints of dogs and cats. Anim. Genet., 18, 1-15.

JEFFREYS, A. J., WILSON, v. AND THEIN, S. L. 1985b. Hypervariable 'minisatellite' regions in human DNA. Nature, 314, 67-73.

JEFFREYS, A. J., WILSON, V. AND THEIN, S. L. 1985c. Individualspecific 'fingerprints' of human DNA. Nature, 316, 76-79.

LANK, S. B., MINEAU, P., ROCKWELL, F. R. AND COOKE, F. 1989. Intraspecific nest parasitism and extra-pair copulation in Lesser Snow Geese. Anim. Behav. 37, 74-89.

LYNCH, M. 1988. Estimation of relatedness by DNA fingerprinting. Mol. Biol. Evol. 5(5), 584-599.

MANWELL, C. AND BAKER, C. M. A. 1975. Molecular genetics of avian proteins. XIII. Protein polymorphism in three species of Australian passerines. Aust. J. Biol. Sci. 28, 545-557.

MORTON, N. E. 1955. Sequential tests for the detection of linkage. Am. J. Hum. Genet., 7, 277-318.

MORTON, N. E. 1957. Further scoring types in sequential linkage tests, with a critical review of autosomal and partial sex linkage in man. Am. J. Hum. Genet., 9, 55-75.

MORTON, E. S., FORMAN, L. AND BRAUN, M. 1990. Extra-pair fertilizations and the evolution of colonial breeding in Purple Martins. Auk 107, 275-283.

MUMME, R. L., KOENIG, W. D., ZINK, R. M. AND MARTEN, J. L. 1985. Genetic variation and parentage in a Californian population of Acorn Woodpeckers. Auk, 102, 305-312.

NEWTON, 1. 1989. (ed.) Lifetime Reproduction in Birds. Academic Press, London.

SHAW, C. R. AND PRASAD, R. 1970. Starch gel electrophoresis of enzymes - a compilation of recipes. Biochem. Genet., 4, 297-320.

WESTNEAT, D. F. 1990. Genetic parentage in the Indigo Bunting. A study using DNA fingerprinting. Behav. Ecol. Sociobiol. 27, 67-76.

WETTON, J. H. 1990. Aspects of the biology of a House Sparrow (Passer domesticus) colony. PhD Thesis, University of Nottingham.

WETTON, J. H., CARTER, R. E., PARKIN, D. T. AND WALTERS, D. 1987. Demographic study of a wild House Sparrow population by DNA fingerprinting. Nature, 327, 147-149.

WETTON, J. H. AND PARKIN, D. T. 1991. An association between fertility and cuckoldry in the House Sparrow Passer domesticus. Proc. Roy. Soc. Lond. B., 245, 227-233.

WREGE, P. H. AND EMLEN, S. T. 1987. Biochemical determination of parental uncertainty in White-fronted Bee-eaters. Behav. Ecol. Sociobiol., 20, 153-160.

ZISCHLER, H., SCHÅFER, R. AND EPPLEN, J. T. 1989. Non-radioactive oligonucleotide fingerprinting in the gel. $\mathrm{Nucl}$. Acids Res., 17, 4411. 